\title{
Familial hypercholesterolemia in developing countries
}

\author{
Abdulhalim Jamal Kinsara* \\ Head of Adult Cardiology, King Saud bin Abdulaziz University for Health Sciences, King Faisal Cardiac Center, Saudi Arabia
}

\begin{abstract}
Familial hypercholesterolemia is a genetic disease with a potential for major mortality and morbidity. Consanguineous marriage is common among certain societies like Saudi Arabia. A brief review of the subject and preliminary results are presented.
\end{abstract}

\section{Introduction}

The International Familial Hypercholesterolemia Foundation has declared that familial hypercholesterolaemia (FH) is going undiagnosed and 200,000 people are dying every year from a family inherited disorder that is easily diagnosed and treatable.

Prevalence of FH and FH-related cardiovascular adverse clinical outcomes in the Saudi population are unknown. With a prevalence of 1 per 500 US people suffering from heterozygous familial hypercholesterolemia, we expect Saudi Arabia with an estimated population of 25,795,9382 to have 51,591 cases, hence raising awareness of Familial Hypercholesterolaemia is an important step

Cross sectional epidemiological data of $\mathrm{FH}$ for a period of two years in Saudi Arabia will be studied. All samples with fasting LDL > $6.5 \mathrm{mmol} / \mathrm{L}$ will be analyzed. Data pertinent to risk will be collected and subjected to statistical analysis. The charts of those patients who had a follow up will be reviewed. Consanguinity and family pedigree will be studied if available.

We had 889 patients with LDL $>6.5 \mathrm{mmol} / \mathrm{L}$ out of 288,696 samples submitted to our laboratory over a 2 year period. Such figures gave an incidence of 1.5 per 500 patients, higher than the reported US figure.

Full epidemiological data, follow up and outcome will be released when the data collection process is completed.

A formal study showed that in a population with a high rate of consanguinity, there is a significant increase in the prevalence of common adult diseases such as cancer, mental disorders, heart diseases, gastrointestinal disorders, hypertension and hearing deficit.

The disease is hereditary in an autosomal dominant manner. Mutation(s) and/or deletion(s) in the LDL-receptor (LDLR) gene, in the apolipoprotein $\mathrm{B}-100$ (ApoB) gene, or in the proprotein convertase subtilisin kexin 9 (PCSK9) genes are the most known causative mutations. In one study, the genetic defects causing FH in the Saudi population showed four common mutations in coding sequences of the LDLR gene, one mutation in ApoB gene and three mutations in PCSK9 gene. The genetic data are important for optimizing cholesterol lowering therapies and mutational analysis diagnostic test [1].

In another 100 cases with $\mathrm{FH}, 25$ mutations in cases in Exon-3 (against 2 mutations in controls), 5 mutations in exon 4 and none of the mutations were identified in exon 8 [2].
The genetic screening program is a cost effective test [3].

Screening with a comprehensive organized disease management program model such as that used in the Netherlands where patients with a confirmed diagnosis are followed in a focused disease management program which addresses correctable lifestyle issues and provides optimal medical therapy, has been very effective and substantially improves outcomes.

A 10-year follow up showed a dramatic improvement in survival that was comparable to non-affected controls with age and sex matched in the Rotterdam study [4-5].

Statins have been the first-line drugs for lowering cholesterol since the late 1980s but many patients with FH are resistant and some develop side effects/intolerance to them.

The new lipid-lowering class; PCSK9 inhibitors are monoclonal antibodies. They target and inactivate a specific protein in the liver, called proprotein convertase subtilisin kexin 9; this dramatically reduces the amount of harmful LDL cholesterol circulating in the bloodstream [6].

Those that fail these measures or confirmed homozygous $\mathrm{FH}$ patients are considered for advanced therapeutic options like LDLapheresis. For Homozygous FH patients, combined heart-liver transplant might prevent cardiovascular death in adolescence or early youth.

Efforts to establish a registry for screening for FH in developing countries is being undertaken to improve recognition, increase awareness and prevent premature atherosclerosis in $\mathrm{FH}$.

Such information is useful to corporate, government and communication leaders for the number one cause of genetic cardiovascular disease worldwide.

Correspondence to: Abdulhalim Jamal Kinsara, Ass Professor, Head of Adult Cardiology, King Saud bin Abdulaziz University for Health Sciences, COM-WR, Mail code: 6599, P.O. Box 9515, Jeddah 2142, Saudi Arabia, Tel: 966-12-2266666; Fax: 920008668; E-mail: Kinsaraaj@ngha.med.sa

Key words: familial hypercholesterolemia; consanguinity; developing countries

Received: July 16, 2016; Accepted: August 10, 2016; Published: August 13, 2016 


\section{References}

1. AL-Allaf F, Athar M, Abduljaleel Z, et al (2014) Identification of novel genetic mutations causing familial hypercholesterolaemia among Saudi Arabian population. American Society of Human Genetics annual meeting, USA.

2. Alharbi KK, Kashour TS, Al-Hussaini W, Nbaheen MS, Hasanato RM, et al. (2015) Screening for genetic mutations in LDLR gene with familial hypercholesterolemia patients in the Saudi population. Acta Biochim Pol. 62: 559-62. [Crossref]

3. Wonderling D, Umans-Eckenhausen MA, Marks D, Defesche JC, Kastelein JJ, et al. (2004) Cost-effectiveness analysis of the genetic screening program for familial hypercholesterolemia in the Netherlands. Semin Vasc Med 4: 97-104. [Crossref]
4. Umans-Eckenhausen MA, Defesche JC, Sijbrands EJ, Scheerder RL, Kastelein JJ. (2001) Review of first 5 years of screening for familial hypercholesterolemia in the Netherlands. Lancet 357: 165-68. [Crossref]

5. Wiegman A, Gidding SS, Watts GF, Chapman MJ, Ginsberg HN, et al. (2015) European Atherosclerosis Society Consensus Panel. Familial hypercholesterolaemia in children and adolescents: gaining decades of life by optimizing detection and treatment. Eur Heart J 36(36): 2425-37. [Crossref]

6. Sabatine MS, Giugliano RP, Wiviott SD, et al. (2015) Efficacy and Safety of Evolocumab in Reducing Lipids and Cardiovascular Events. N Engl J Med 372: 15001509 .

Copyright: (C2016 Kinsara AJ. This is an open-access article distributed under the terms of the Creative Commons Attribution License, which permits unrestricted use, distribution, and reproduction in any medium, provided the original author and source are credited. 